\title{
A Conferência que virou (quase só) história
}

\section{The Conference that became (almost only) history}

\section{La Conferencia que se convirtió (casi solo) en historia}

\author{
João Caldeira Brant Monteiro de Castro ${ }^{1, a}$ \\ joaocbrant@gmail.com | https://orcid.org/0000-0002-2875-7721 \\ ${ }^{1}$ Observatório Latino-Americano de Regulação, Meios e Convergência. Rio de Janeiro, RJ, Brasil. \\ a Doutorado em Ciência Política pela Universidade de São Paulo.
}

\section{Resumo}

Esta nota de conjuntura avalia o processo decorrente da I Conferência Nacional de Comunicação (Confecom), tendo em vista o marco de dez anos de sua realização. O autor argumenta que o principal resultado da Conferência foi abrir espaço para o Estado brasileiro superar a ausência de um sistema regulatório e de regras que redesenhassem o sistema de comunicação brasileiro. Ao decidir não ocupar este espaço aberto, o governo federal perdeu a última oportunidade que se abriu para estabelecer uma nova dinâmica para o setor. São analisadas também as modificações no cenário político e econômico desde a realização da Conferência. $\mathrm{O}$ autor conclui que, embora os apontamentos dados pela Confecom em relação à convergência tecnológica não respondam a especificidades do momento atual, poderiam, se tivessem sido efetivados, ter preparado o país para enfrentar os desafios novos e conter a força política e econômica dos atores do setor.

Palavras-chave: Comunicação; Conferência Nacional; Sociedade civil; Estado brasileiro; Políticas públicas.

\begin{abstract}
This conjuncture note assesses the process resulting from the I Conferência Nacional de Comunicação Confecom (I Communication National Conference), in view of the ten-year mark of its realization. The author argues that the main result of the Conference was to open space for the Brazilian State to overcome the absence of a regulatory system and rules that could redesign the Brazilian communication system. In deciding not to occupy this open space, the Federal Government missed the last opportunity that opened up to establish a new dynamic for the sector. Changes in the political and economic scenario since the Conference were also analyzed. The author concludes that, although the outcomes of the Confecom regarding technological convergence do not respond to specificities of the present moment, they could, if they had been implemented, have prepared the country to face the new challenges and contain the political and economic strength of the sector players.
\end{abstract}

Keywords: Communication; National Conference; Civil society; Brazilian State; Public policy. 


\section{Resumen}

Esta nota de coyuntura evalúa el proceso resultante de la I Conferência Nacional de Comunicação Confecom (I Conferencia Nacional de Comunicación), en vista de los diez años de su realización. El autor argumenta que el principal resultado de la Conferencia fue abrir un espacio para que el Estado brasileño supere la ausencia de un sistema regulatorio y reglas que rediseñarían el sistema de comunicación brasileño. Al decidir no ocupar este espacio abierto, el Gobierno Federal perdió la última oportunidad que se abrió para establecer una nueva dinámica para el sector. También se analizaron los cambios en el escenario político y económico desde la Conferencia. El autor concluye que, aunque las respuestas dadas por la Confecom con respecto a la convergencia tecnológica no respondan a especificidades del momento actual, si hubieran sido implementadas, podrían haber preparado al país para enfrentar los nuevos desafíos y contener la fuerza política y económica de los actores del sector.

Palabras clave: Comunicación; Conferencia Nacional; Sociedad civil; Estado brasileño; Políticas públicas.

\section{Introdução}

Em dezembro de 2019, completaram-se 10 anos da realização da I Conferência Nacional de Comunicação (Confecom). A despeito da enorme mobilização que ela gerou, seus resultados tiveram pouco impacto na agenda de governo dos anos seguintes. Neste período, a conjuntura política do Brasil mudou completamente, assim como o cenário econômico nas comunicações. Qualquer balanço sobre os resultados da Conferência precisa levar em conta essas alterações no contexto político e econômico. Ainda assim, um olhar atento sobre o processo que sucedeu à Conferência evidencia que seus resultados são hoje mais um documento histórico do que um roteiro que tenha se concretizado e tenha impactos no presente.

O argumento central desta análise é que o resultado principal da Conferência foi abrir espaço para o Estado brasileiro superar a ausência de um sistema regulatório e de regras que redesenhassem o sistema de comunicação brasileiro com base na Constituição Federal de 1988. Ao decidir não ocupar este espaço aberto, o governo federal perdeu a última oportunidade que se abriu para estabelecer uma nova dinâmica para o setor. Sem pressão relevante da sociedade civil, a possibilidade de as propostas de mérito mais relevantes serem implementadas reduziu-se a quase zero.

\section{A história da I Conferência Nacional de Comunicação}

Desde 2007, as organizações da sociedade civil que atuavam na defesa da democratização da comunicação se organizaram em uma Comissão Pró-Conferência Nacional de Comunicação, que conseguiu o apoio da Comissão de Direitos Humanos e Minorias e da Comissão de Legislação Participativa da Câmara dos Deputados. Entre 2007 e 2008, aconteceram diversas atividades e reuniões com o governo federal, em defesa da Conferência. Até 2008, o governo já havia realizado 51 conferências temáticas em várias áreas¹, o que ajudava a justificar a pressão para se realizar a de comunicação.

Naquele ano, completavam-se 20 anos da Constituição Federal, e vários dos artigos do capítulo da comunicação social permaneciam sem regulamentação, inclusive os que tratavam da proibição a monopólios e oligopólios. O governo federal já havia recuperado os índices de popularidade que haviam caído com o mensalão e enfrentava uma conjuntura menos adversa do que em anos anteriores. Ao mesmo tempo, a estrutura econômica do mercado de comunicações impunha um rearranjo, pelo crescimento da internet e das opções de transmissão audiovisual. 
Nesse contexto, no início de 2009, o governo federal decidiu convocar a Conferência. A comissão organizadora reuniu, num primeiro momento, setores empresariais, entidades da sociedade civil e representantes do governo federal e do Parlamento. A participação das empresas de televisão era estratégica para dar legitimidade política ao processo, como reconhece o ex-ministro Franklin Martinsi. A opção do governo foi, então, criar alguns compromissos prévios. O governo não apoiaria nenhuma proposta que tivesse a expressão "controle social da mídia". Ao mesmo tempo, estabeleceu-se um quórum qualificado de 2/3 para se aprovar as propostas ${ }^{\mathrm{ii}}$.

Mesmo com essas garantias, as principais empresas da área de mídia optaram por deixar o processo organizativo da Conferência. Em agosto de 2009, a Globo liderou o movimento pela saída das entidades

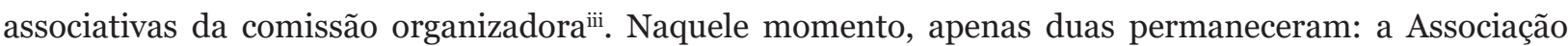
Brasileira de Telecomunicações (TeleBrasil), que reunia as empresas de telecomunicações, e a Associação Brasileira de Radiodifusão, que reunia Bandeirantes e RedeTV. A etapa nacional da Conferência aconteceu em dezembro de 2009 com mais de 1.500 delegados, e foram aprovadas 633 propostas.

\section{Os resultados da Conferência}

A análise sobre as propostas aprovadas permite consolidar três conclusões:

- o conjunto das resoluções refletia majoritariamente a pauta da sociedade civil organizada que atuava pela democratização de comunicação. Isso não significa que sua agenda tenha sido aprovada tal qual apresentada - propostas que o governo não apoiou não foram aprovadas -, mas que o sentido geral das propostas aprovadas era esse;

- cerca de 90\% das 633 propostas foram aprovadas por consenso ou maioria super qualificada (mais de 80\% de apoio) ainda nos Grupos de Trabalho. Isso significa que elas não eram, em si, polêmicas ou sensíveis para qualquer setor envolvido;

- a grande maioria das propostas, inclusive aquelas aprovadas em plenária, tem aderência às práticas de regulação democrática praticadas em democracias consolidadas da Europa e América do Norte, e estava totalmente em linha com a Constituição Federal de 1988.

Em maio de 2010, após Hélio Costa se desincompatibilizar do Ministério das Comunicações para disputar o governo de Minas Gerais, o ministro Franklin Martins iniciou um debate interno no governo com técnicos de oito áreas para construir um anteprojeto de lei de comunicação social eletrônica. $\mathrm{O}$ texto foi sendo costurado pela Secretaria de Comunicação (Secom), com Franklin Martins à frente, e foi discutido com o presidente Lula. Em novembro, o governo realizou um seminário internacional reunindo órgãos reguladores de todo o mundo. A proposta final do anteprojeto de lei ficou pronta em dezembro, e tinha mais de 200 artigos, segundo o ministro ${ }^{\text {iv }}$.

Com a saída do presidente Lula, o texto foi entregue para a nova presidente, Dilma Rousseff, e para o novo ministro das Comunicações, Paulo Bernardo. A opção da presidente, contudo, foi não dar publicidade ao texto nem continuidade ao processo de discussão sobre o novo marco regulatório para as comunicações.

Os motivos políticos para a opção de Dilma Rousseff não são claros, mas é possível vislumbrar algumas hipóteses factíveis (e não excludentes) a partir de entrevistas realizadas para a tese de doutorado realizada por este autor3: 1) Dilma assumia o mandato sob a sombra de Lula, e precisava criar marca própria e conquistar apoio ao assumir. A opção de dar continuidade a debate com evidente potencial de desgaste poderia fragilizá-la politicamente em início de mandato; 2) Franklin Martins tinha problemas de diálogo

\footnotetext{
i Em entrevista concedida ao autor em outubro de 2017.

ii Em entrevista concedida ao autor em outubro de 2017.

iii Em entrevista concedida ao autor em outubro de 2017.

iv Em entrevista concedida ao autor em outubro de 2017.
} 
com a Globo ${ }^{v}$ e era visto como um interlocutor duro. A não continuidade de seu projeto dava um sinal de bandeira branca na relação com as empresas; 3) Não é evidente que Dilma Rousseff tivesse, àquela altura, clareza sobre se havia necessidade de um novo marco regulatório para o setor. Já em julho de 2010, a então candidata afirmou que era rigorosamente contra qualquer controle para a mídia e que o melhor controle era o controle remoto 4 .

A resposta pode estar também em uma análise mais prosaica, que reconhece que o conflito entre governo e empresas é imperativo para qualquer transformação relevante desse cenário. Nesse sentido, os governos precisariam se perguntar se a disputa tem como ser vencida, ou seja, se é possível aprovar no Congresso Nacional um projeto cujo resultado efetivo seja a desconcentração e diminuição do poder dos meios de comunicação, ou se a disputa só vai gerar desgastes políticos sem resultados práticos. Considerando que deputados e senadores dependem de cobertura favorável para se reeleger e que, inclusive, parte deles é proprietária de veículos de comunicação, a pergunta parece central.

\section{Brechas e luzes}

Em publicação recente, Octavio Pieranti ${ }^{5}$ analisou os resultados da Conferência e concluiu que $26 \%$ das 470 propostas que são mensuráveis (não apenas principiológicas) foram implementadas parcialmente, e 9\% foram implementadas totalmente. Os temas que tiveram mais propostas implementadas foram produção independente e regional, sistema de outorgas, propriedade, internet, e telecomunicações. TV por assinatura e internet foram justamente as duas áreas em que o governo federal conseguiu ajudar a impulsionar um novo cenário regulatório e uma política mais robusta.

Em 2011, a existência de interesses conflitantes entre diferentes setores permitiu a aprovação da nova lei que organizou o setor de TV por assinatura, depois de quatro anos de negociação no Congresso Nacional com a participação da Agência Nacional do Cinema (Ancine) e do Ministério da Cultura. A Lei 12.485/2011 pôde ser aprovada por representar um conjunto de interesses diversos - empresas de telecomunicações, de televisão e produtores independentes obtiveram vitórias com o texto final. Uma vez sancionada, a lei representou um avanço significativo na promoção da diversidade cultural.

Em todo o tocante à televisão aberta, contudo, o assunto seguiu estagnado. Depois de movimentações intensas do próprio Partido dos Trabalhadores (PT) em defesa de um novo marco regulatório para as comunicações $^{\text {vi }}$, em fevereiro de 2012 o ministro Paulo Bernardo chegou a anunciar que retomaria o tema por meio de uma consulta pública feita em forma de perguntas ${ }^{6}$, mas a consulta não chegou a ser lançada. Esse foi o último suspiro dos governos do PT em relação a esse tema.

No semestre seguinte, o Fórum Nacional pela Democratização da Comunicação, que reúne entidades da sociedade civil que atuam sobre o tema, lançou uma campanha para coletar assinaturas em apoio a um Projeto de Lei de Iniciativa Popular intitulado Lei da Mídia Democrática 7 . Vários estados chegaram a lançar a campanha, mas o número de assinaturas para apresentar o projeto ao Congresso Nacional não foi atingido.

Com a esquiva em relação à regulação da radiodifusão, o foco foi para as políticas de internet. Logo em seu primeiro ano, a presidenta Dilma Rousseff apresentou ao Congresso o projeto do Marco Civil da Internet, que já vinha sendo discutido desde 2009 no âmbito do Ministério da Justiça. Dois anos depois, a denúncia de Edward Snowden de que os Estados Unidos mantinham esquemas de vigilância sobre líderes

\footnotetext{
v Franklin Martins foi comentarista político na emissora até abril de 2006, quando não teve seu contrato renovado. Ele também dirigiu os processos de democratização da verba publicitária e de realização da Confecom, que não eram do interesse político da emissora.

vi A movimentação do PT incluiu, entre setembro e dezembro de 2011, os seguintes passos: aprovação de moção no Congresso realizado em setembro, realização de seminário nacional sobre o tema em novembro e aprovação de resolução no Diretório Nacional em dezembro. Uma das propostas aprovadas foi a de realização de uma campanha em diálogo com a sociedade civil.
} 
políticos de vários países, inclusive do Brasil, levou a presidenta a ampliar a articulação internacional sobre o tema e dar peso político à tramitação do Marco Civil.

No campo da internet, a aprovação do Marco Civil estabeleceu direitos para os usuários da rede, garantindo a neutralidade da rede e a liberdade de expressão. A Lei 12.965/2014 foi considerada uma das mais avançadas do mundo em garantia de direitos na rede, mas sua regulamentação foi publicada apenas um dia antes da saída de Dilma da presidência.

\section{Fechamento dos espaços e mudança de cenário}

As manifestações de 2013 inauguraram um novo momento político no país. Em pouco mais de um mês, as jornadas de junho promoveram um quase 'reset' na agenda política, e evidenciaram o crescimento da internet como ambiente de informação e organização ${ }^{8}$. A presidenta Dilma Rousseff sobreviveria às eleições de 2014, mas a combinação da operação Lava-Jato com a crise econômica deu força ao impeachment que resultou em sua saída em maio de 2016.

Com a saída do PT da Presidência da República e a assunção de Temer, a agenda resultante da Confecom deixou de estar até no horizonte. Na única ação relevante para o setor, o presidente publicou o decreto 9.138/2017, que modificou o regulamento do serviço de radiodifusão (TV e rádio). Com o discurso de desburocratização, o governo na verdade simplificou o processo de renovação automática que eterniza as concessões de comunicação no Brasil. A despeito de mudanças pontuais apontadas por Pierantín, não houve desde a Confecom nenhuma alteração que modificasse o cenário legado pela ditadura militar para a radiodifusão, que segue intocado.

Ao mesmo tempo que a agenda da Confecom ficava apenas como memória de um período em que se abriram oportunidades de transformação, o cenário econômico modificava significativamente a realidade do setor. Empresas de televisão brasileiras disputam tempo de audiência e verba de publicidade com transnacionais como Google/YouTube e Facebook. Provedores de vídeo por demanda, como Netflix, disputam público com operadores de TV por assinatura. Consolidou-se um novo cenário de negócios nas comunicações, sustentado na gestão e tratamento de dados pessoais.

Dez anos atrás, embora a convergência já começasse a ganhar corpo, era impossível saber o peso que cada serviço e cada setor ganharia no novo cenário. Os apontamentos dados pela Confecom em relação ao tema não respondem a especificidades do momento atual, mas poderiam, se tivessem sido efetivados, ter preparado o país para enfrentar os desafios novos e conter a força política e econômica dos atores do setor.

\section{Conclusão}

O quadro geral das políticas de comunicação desde a I Conferência Nacional de Comunicação foi de estagnação na televisão aberta e na mídia em geral, e avanços na televisão a cabo e na internet. Paralisados pela ausência de estratégia e pela dúvida sobre os possíveis resultados, os governos progressistas tornaramse vítimas de sua própria estagnação no tratamento desse problema.

Oimpeachment deDilma encerrou um ciclo de quatroperíodos presidenciais do Partidodos Trabalhadores com a ruptura definitiva de um pacto que possibilitou a chegada de Lula ao poder em 2003. Nos dez anos que nos separam da realização da Confecom, o cenário das comunicações mudou completamente, mas a falta de ferramentas para garantir o interesse público ante o poder político e econômico das grandes empresas permanece a mesma. 


\section{Referências}

1. Balanço de Governo (BR) [Internet]. 2010 [citado 4 mar 2020]. Disponível em: http://www. balancodegoverno.presidencia.gov.br/democracia-e-dialogo/1.-participacao-social.

2. Empresas de mídia se desligam de organização de evento do governo. Folha de S.Paulo. 2009 14 ago [citado 4 mar 2020]; Ilustrada:A10. Disponível em: https://www1.folha.uol.com.br/ ilustrada/2009/08/609663-empresas-de-midia-se-desligam-de-organizacao-de-evento-do-governo.shtml.

3. Castro JCBM. A atuação das empresas de televisão como grupo de interesse: estratégias e táticas de pressão no caso da política de classificação indicativa [Tese]. São Paulo: Universidade de São Paulo; 2018.

4. Ceolin A. Dilma afirma que único controle da mídia é "o controle remoto". Último segundo. 2010 [citado 4 mar 2020]. Disponível em: https://ultimosegundo.ig.com.br/eleicoes/dilma-afirma-que-unico-controleda-midia-e-o-controle-remoto/n1237724826114.html.

5. Pieranti OP. Confecom, 10 anos depois: um debate necessário sobre a implementação das propostas aprovadas. Chasqui [Internet]. 2019 [citado 4 mar 2020];(141):275-88. Disponível em: https:// revistachasqui.org/index.php/chasqui/article/view/3837.

6. Marco regulatório da mídia vai à consulta pública [Internet]. Brasília: Fenaj; 2012 [citado 4 mar 2020 ]. Disponível em: http://fenaj.org.br/marco-regulatorio-da-midia-vai-a-consulta-publica/.

7. Projeto de Lei de Iniciativa Popular da Comunicação Social Eletrônica (Lei da Mídia Democrática) [Internet]. Brasília: Fórum Nacional pela Democratização da Comunicação; 2015 [4 mar 2020]. Disponível em: http://www.paraexpressaraliberdade.org.br/projeto-de-lei/.

8. Brant J. Política e comunicação nas jornadas de junho. Rio de Janeiro: Fundação Ford; 2013. 